\title{
A morte de Florestan. e a morte da memória
}

JOSÉ DE SOUZA MARTINS

F ALAR DA VIDA E DA OBRA do professor Florestan Fernandes numa celebração motivada por sua morte implica, no meu modo de ver, considerar o sentido dessa morte para resgatar o sentido dessa vida. A morte do professor Florestan atinge de modo particularmente intenso a Universidade de São Paulo porque inevitavelmente põe na pauta das nossas reflexões o grave tema da morte intelectual. A morte que, de algum modo, foi imposta a boa parte dos que foram vítimas da intervenção da ditadura militar na Universidade, especialmente em 1969 (1). A interrupção de carreiras promissoras, a expulsão de cientistas e pensadores da maior competência, tinha como objetivo a interdição do pensamento crítico, do conhecimento comprometido com a definição de um destino emancipador e justo para a sociedade brasileira. Nas pessoas de seus docentes vitimados, vítima foi a Universidade e vítima foi o Brasil.

Fui aluno e fui auxiliar de ensino do professor Florestan Fernandes. Sou um membro da geração órfã, como a classifiquei numa dedicatória de livro há alguns anos, classificação que o professor Florestan comentou em artigo de jornal tempos depois. Não posso deixar de falar como membro dessa geração. A orfandade de minha geração é uma orfandade real porque na fase mais importante de nossa formação fomos privados da convivência cotidiana com alguns dos melhores pesquisadores que as ciências sociais já tiveram no Brasil. Além disso, fomos sobrecarregados de obrigações docentes durante os anos mais fundamentais de nossa formação, forçados pelas circunstâncias a preparar nossas teses simultaneamente com obrigações docentes pesadíssimas, especialmente entre 1970 e 1975 (2). Nesse período, fiz o meu doutorado sem qualquer orientação efetiva, quase que autodidaticamente, o que só foi possível pelo aprendizado anterior no sólido curso de graduação em Ciências Sociais, em grande parte ministrado pelos mesmos professores cassados em 1969, e em conseqüência da convivência de cinco anos com o grupo do professor Florestan, seus seminários informais e o debate acadêmico e informal que nele se travava. Ao mesmo tempo em que fazia o doutorado nessas condições, fui o responsável pelas aulas expositivas da disciplina de Introdução à Sociologia, nos turnos diurno e noturno, ministrada a alunos matriculados em vários currículos, o que trazia para a sala de aula regularmente entre 400 e 500 estudantes. Quando falam nas vítimas da ditadura 
no meio acadêmico, raramente as pessoas se lembram das vítimas que ficaram, como os membros da geração órfã, submetidos a condições extremamente adversas de trabalho, incluindo nelas um clima cotidiano corrosivo de repressão policial e institucional, sem contar o oportunismo dos que se aproveitaram das cassações para acelerar carreiras e ocupar posições sem ter de efetivamente disputá-las.

A repentina cassação de professores, anunciada em $A$ Voz do Brasil de um começo de noite de abril de 1969, criou para as Ciências Sociais entre nós um irremediável vazio no espaço de criatividade que havia sido inaugurado pelos membros da missão universitária francesa, responsável pela fundação da Universidade de São Paulo em 1934, e que ganhara inesperada consistência no empenho, na competência e na obra de seus alunos e continuadores brasileiros. $O$ professor Florestan, mais de uma vez, disse que o grupo de cientistas sociais do qual veio a fazer parte e se tornaria a espinha dorsal não constituía, propriamente, uma escola de pensamento. Acredito, porém, que nisso ele se enganava. Criouse de fato na Faculdade de Filosofia uma escola sociológica, marcada menos pela unanimidade teórica e muito mais pela qualidade de definição teórica e interpretativa dos problemas de investigação, de liberdade de opção entre possibilidades teóricas, de inovação temática; de competência no lidar conjuntamente com a diversidade de orientações metodológicas da sociologia; muito mais pelo rigor científico, pela pertinência das indagações, pela criatividade, pela capacidade de criar sem infra-estrutura, sem apoio e sem dinheiro. Marcada muito mais pela capacidade de fazer pesquisa de vanguarda, de apontar os temas que reclamavam problematização e interpretação, de associar o ensino à pesquisa, de formar quadros. Significativamente, uma das conseqüências da exclusão da Universidade dos membros desse grupo, pela ditadura militar, foi o rápido empobrecimento de perspectivas na definição de temas e problemas da investigação sociológica e o abandono quase generalizado das grandes problematizações que $o$ grupo havia desenvolvido, essenciais, para dar continuidade ao estabelecimento de uma sociologia brasileira, uma sociologia enraizada, apoiada na própria criatividade teórica do grupo e na sua própria pesquisa metodológica, como pretendia e em grande parte havia conseguido o professor Florestan. Em seu lugar surgiu o que chamo de sociologia colonizada, uma sociologia dedicada a temas importados e da moda, não raro estranhos ao essencial de nossa própria realidade social. Uma sociologia alienada, oposta à sociologia que Florestan Fernandes propunha.

Curiosamente, esse empobrecimento atingiu de modo radical tanto o grupo que substituiu na Universidade os professores que se foram, quanto atingiu também os pesquisadores excluídos que se agruparam em centros privados de pesquisa, como o Cebrap. É significativo que nenhum dos pesquisadores afastados e agrupados posteriormente nesses centros, e outros que surgiram depois e se tornaram moda, tenha produzido obra equiparável às que eles próprios haviam 
produzido enquanto estavam na Universidade. Evidentemente, porque o criativo projeto desenvolvido na USP foi interrompido, as grandes e significativas indagações, que eram`ao mesmo tempo teóricas e históricas, já não podiam ser adequadamente tratadas no âmbito restrito de um universo de pesquisa tendente à investigação instrumental. A pesquisa perdeu o seu caráter acadêmico e teve de se submeter às urgências e às limitações de demandas restritas a indagações que não podem ser consideradas historicamente fundamentais nem teoricamente relevantes. $O$ que evidentemente não significa subestimar a importância e a qualidade de artigos e livros originados dessas instituições.

Isso se deu também porque, ao intervir na Universidade, a ditadura interrompeu ou, ao menos, mutilou o compromisso da ciência com a sociedade, que era componente implícito no projeto da missão universitária francesa e mais importante se tornou na obra e na ação de seus sucessores brasileiros. Particularmente no grupo cuja identidade se definiu na figura do professor Florestan Fernandes, o projeto era o de consolidar uma instituição acadêmica de alto rigor científico e, ao mesmo tempo, fazer uma ciência comprometida com as possibilidades de transformação da sociedade brasileira, de modo a superar seus muitos componentes oriundos da herança colonial, responsáveis pelo atraso social e político, pelas injustiças, pela ignorância, pela pobreza. É verdade que a ação deletéria da ditadura se, de um lado, corroeu as bases desse projeto educacional, de outro lado levou à partidarização da dimensão propriamente política desse projeto.

Não é acidental que dois membros desse grupo tenham chegado à política: Fernando Henrique Cardoso, antigo aluno e assistente do professor Florestan, tornou-se senador e é agora presidente da República. Bem vistas as coisas, a base sociológica de sua ação governamental ainda pode ser facilmente encontrada num projeto de pesquisa elaborado pelo professor Florestan Fernandes, em 1962, o famoso projeto Economia e sociedade no Brasil (Análise sociológica do subdesenvolvimento) (3). Esse projeto era uma síntese dos projetos de pesquisa dos vários assistentes do professor Florestan, incluindo o projeto específico do próprio Fernando Henrique Cardoso. Com orientação diversa, mas enraizada em muitos aspectos do projeto Economia e sociedade no Brasil, o professor Florestan tornou-se deputado federal. É claro que a partidarização teve alcance maior e menos visível do que o desses casos espetaculares, levando numeroso grupo de alunos e professores aos partidos políticos, basicamente os de oposição à ditadura, fazendo de vários deles, com o tempo, membros influentes de governos locais e estaduais. Curiosamente, hoje a partidarização de alunos e docentes, sobretudo destes últimos, é certamente o principal entrave, na Universidade, sobretudo nas ciências sociais e nas ciências humanas, ao desenvolvimento científico na concepção criativa que caracterizou a fase fecunda da permanência na Instituição dos docentes que foram cassados. É que muitos já não conseguem, em 
nome da militância, distinguir entre ciência e ideologia, coisa que na boa escola do professor Florestan sempre se distinguiu. $O$ que lhe valeu freqüentes acusações de positivismo e ecletismo, como se ambos fossem defeitos.

Mesmo aqueles que tiveram a oportunidade de retomar a vida docente na universidade particular, como se deu com os que foram para a Universidade Católica, como ocorreu com o próprio professor Florestan, não encontraram ali as mesmas possibilidades materiais e institucionais de que haviam disposto quando estavam na Universidade de São Paulo. Na USP, a pesquisa científica e original é o objetivo principal. A docência é decorrência dela, é uma função derivada, no sentido de que pesquisa e ensino não se separam. $O$ verdadeiro desenvolvimento científico em escala significativa só pode se dar nesse tipo de ambiente, o que em nossos tempos só parece ser possível na universidade pública. $\mathrm{O}$ âmbito da criação científica fica muito comprometido quando há limitações para a dedicação exclusiva à docência e à pesquisa e quando o tempo especialmente reservado ao trabalho científico é sacrificado pelo tempo de trabalho dedicado à docência. Não desconheço, obviamente, a importância do convite generoso que thes foi dirigido pela Pontifícia Universidade Católica de São Paulo (4). Ela lhes ofereceu, sobretudo, a possibilidade do reencontro com alunos na sala de aula, fator essencial de indagação e criatividade de que os centros privados de pesquisa não dispõem, a não ser ilusoriamente, como às vezes acontece quando instauram programas paralelos e concorrentes de ensino a número restritíssimo de alunos que são, na verdade, estudantes da Universidade. Esse artificio não substitui a convivência efetiva com alunos de todos os níveis em verdadeiras salas de aula.

O professor Florestan, mesmo convidado, não se vinculou ao centro de pesquisa criado para abrigar os docentes afastados compulsoriamente da Universidade de São Paulo (5). Acabou aceitando convite para assumir uma cátedra na Universidade de Toronto, que lhe deu até melhores condições de trabalho do que aquelas que a usp lhe havia oferecido até o início de 1969 e certamente melhores do que qualquer centro de pesquisa poderia oferecer-lhe no Brasil. Ele chegou a dizer que o período do Canadá, apesar do exílio, foi o mais feliz de sua vida intelectual. O que se compreende, $\mathrm{já}$ que se trata de uma grande universidade, capaz de oferecer a seus docentes, como de certo modo ocorria e ainda ocorre na USP, as condições básicas para o trabalho propriamente criativo, sem a necessidade do subterfúgio de projetos paralelos de tipo instrumental. Ele rapidamente tornou-se professor-residente, com tenure, o que significa ter-se tornado professor efetivo, sem qualquer instabilidade nas suas condições de trabalho.

O grupo da USP também pode ser definido como escola porque foi capaz de formular com grande competência as perguntas, isto é, os problemas de investigação, que norteariam o seu trabalho científico e, ainda que com as limitações das circunstâncias políticas, o das gerações seguintes. Ao falar desse grupo 
não me refiro exclusivamente ao professor Florestan e a seus assistentes. Refirome a eles e à tradição de trabalho acadêmico do grupo de cientistas sociais que atuou com os professores franceses e com o professor Fernando de Azevedo. Eles fizeram o principal de seu trabalho em época singùlar, época de indagações essenciais na nossa história social e na própria história da sociologia. E nos legaram essas indagações e as pistas para respondê-las. Muitos de nós e de nossos alunos trabalhamos ainda com os problemas que eles propuseram (6).

Já que hoje em dia buscamos apreços no exterior e só no exterior cremos que se localizam as fontes válidas de reconhecimento intelectual (no fundo, colonizador), vale a pena lembrar alguns fatos. Para se ter idéia da qualidade do que faziam os membros do grupo de São Paulo, basta lembrar que Robert K. Merton incluiu Florestan Fernandes na lista de meia dúzia dos que em uns poucos países seriam os grandes nomes da Sociologia nos anos 50 e 60, ao comentar seu ensaio sobre o método de interpretação funcionalista (7). Na referência de Merton, o professor Florestan está entre os três primeiros sociólogos que retomaram esse método de explicação e lhe deram a dimensão que alcançaria naquele período.

Aliás, foi somente em 1960, numa conferência em Cambridge, que T.H. Marshall instou aquela Universidade a admitir a Sociologia como disciplina científica regular em seu currículo (8). O grande e influente nome da sociologia inglesa, resultado daquele convite e apelo, é o de Anthony Giddens. Giddens é bem a indicação do pioneirismo competente do grupo de São Paulo, cuja obra, aliás, ele não conhece: as grandes orientações do trabalho do conhecido sociólogo inglês estão, nos últimos $\mathbf{2 0}$ anos, muito próximas do que Florestan fez 20 anos antes. Uma das grandes marcas da sociologia de Giddens, que é a proposta de superar os limites positivistas da descrição e da explicação, e fazer da sociologia um instrumento de crítica social cientificamente fundamentada, já estava presente na sociologia da USP nos anos 50: tanto na obra de Antonio Candido, sobre a educação e sobre o caipira, quanto na de Florestan e seus assistentes. Esse foi e tem sido um traço persistente da sociologia do grupo de São Paulo

Além disso, quase 20 anos antes de que Giddens trabalhasse conjuntamente as grandes influências teóricas dos três autores fundamentais da sociologia - Durkheim, Weber e Marx -, Florestan Fernandes já o havia feito com grande rigor. Ele resgatara a importância, e os limites, que cada uma das orientações metodológicas desses autores tem na construção da moderna teoria social (9).

Sua obra, além do mais, resgatou como componente do próprio pensamento sociológico o que pode ter sido a grande inspiração de vários membros da missão universitária francesa: o de encarar o Brasil como uma laboratório de pesquisa, uma base empírica de questionamento do cientificismo, do racionalismo e do secularismo europeus. Isso está sugerido por Claude Lévi-Strauss e muito 
presente na criativa e inspirada sociologia de Roger Bastide, um sociólogo atento aos aspectos da vida social que, por si mesmos, sugerem a dúvida com relação às grandes interpretações sociológicas européias e metropolitanas; no que somos diferentes daquilo que está nos tratados e manuais que consagram uma concepção eurocêntrica da sociedade. Essas diferenças da nossa sociabilidade tornaramse essenciais naquilo que pode ser legitimamente considerado próprio da tradição sociológica da USP.

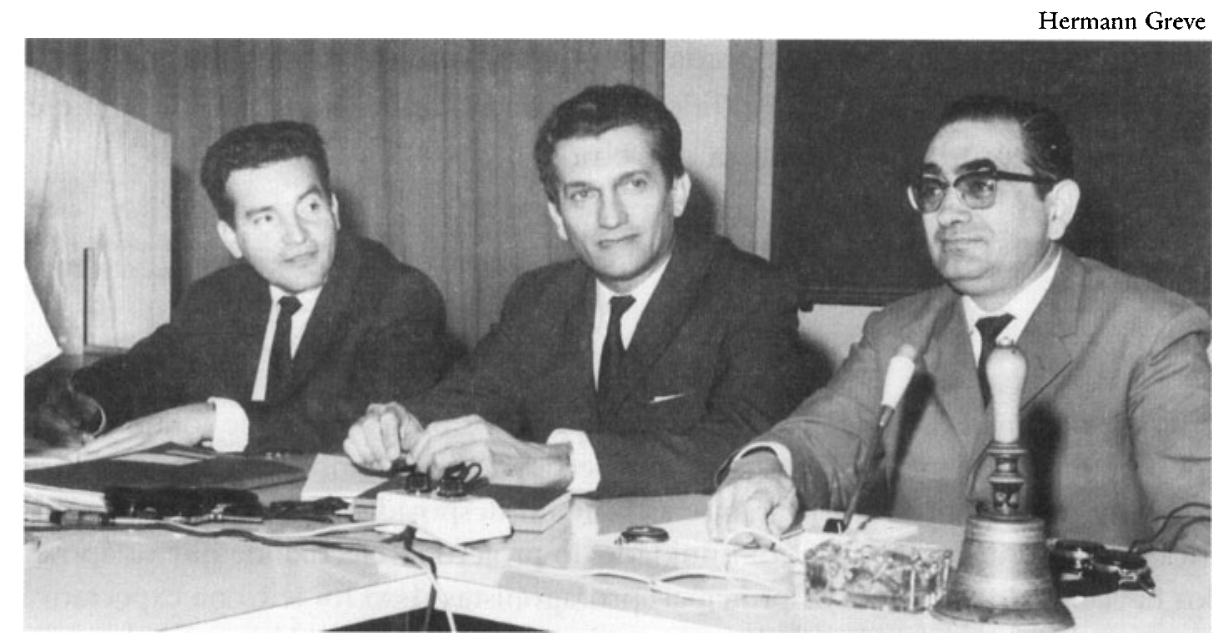

Orlando Fals Borda, Celso Furtado e Florestan Fernandes na Alemanha

A retomada dos clássicos fundamentais significava descobrir neles, nesse encontro estranho e, segundo alguns, impossível, justamente aquilo que sua leitura compartimentada escamoteava: as sociabilidades singulares, as historicidades esquecidas. O que Florestan propunha, e não só ele, era justamente encontrar nesse desencontro teórico os meios de interpretar uma sociedade como a nossa, marcada pela coexistência e interpenetração de tempos e ritmos históricos desiguais, desencontrados. Essas idéias ganhariam força em livros como Sociedade de classes e subdesenvolvimento e $A$ revolução burguesa no Brasil. Essas idéias estavam também presentes na obra de seus colegas e de seus assistentes.

Justamente por isso, não é surpresa encontrar na obra de Florestan Fernandes e do grupo da USP interpretações até mais elaboradas do que as que sobre temas similares foram desenvolvidas em outros centros. Rotulações conceituais que não foram produzidas aqui, mas que têm hoje curso fácil nos meios acadêmicos, tratam de questões que foram tratadas por ele muito antes de se tornarem moda. Foi somente em 1980 que Orlando Fals Borda sistematizou e divulgou suas idéias sobre a chamada pesquisa participante ou pesquisa-ação. A inegável importância de sua proposta metodológica teve e tem enorme repercussão em muitos países. Poucos sabem, porém, que foi na pesquisa sobre os negros, nos anos 50, feita juntamente com Roger Bastide, que Florestan Fernandes desenvolveu a técnica de pesquisa posteriormente difundida sob aquele nome. 
Temas que ganhariam depois importância central e conceituação própria nas ciências sociais, como a chamada dependência (já nos anos $\mathbf{5 0}$ denominada por ele de heteronomia) estão enunciados e formulados em muitos aspectos de seus trabalhos. Uma leitura atenta de seus livros já revela a presença desses temas que ganhariam destaque nos anos recentes, sem que, no entanto, os novos sociólogos se dêem conta de sua presença oculta em seus próprios trabalhos.

No fim de tudo, portanto, sua morte nos fala de outra morte, a morte da memória; nos fala de uma deliberada falta de continuidade institucional, na própria Universidade de São Paulo, da tradição de trabalho científico de que ele foi certamente o grande protagonista entre nós.

\section{Notas}

1 Considero vítimas da ditadura militar não apenas os professores que foram aposentados compulsoriamente e afastados da Universidade, mas também os alunos e, principalmente, os docentes que ficaram e assumiram despojada e expressamente a missão ética e política de assegurar a continuidade do projeto intelectual de que os aposentados haviam sido até então os principais protagonistas. Isso foi feito na expectativa de que o projeto teria continuidade, sobretudo com o retorno à Universidade, um dia, dos professores dela injustamente afastados. Isso, infelizmente, nào ocorreu, pois a maior parte deles, inclusive o professor Florestan Fernandes, recusou a anistia concedida em condições humilhantes pela própria ditadura militar. Convém lembrar que, no caso das antigas cadeiras de Sociologia c de Ciência Política, jovens docentes tiveram de deixar a Universidade por razốes políticas, scm dircito à aposentadoria proporcional ao tempo de serviço è à anistia que viria depois. É preciso que se ressalte, além do mais, que os docentes nesta última situação foram, por proposta minha à assembléia departamental, readmitidos pelo Departamento de Ciências Sociais, sucessor daquelas antigas cadeiras. Refiro-me aos professores Claudio Vouga, Eduardo Kugelmas e Lourdes Sola. A professora Lourdes Sola, num primeiro momento recusou a integração por ter outros interesses que a tornavam inviável, mas, mais tarde, aceitou ser reintegrada no Departamento de Ciência Política.

2 No meu caso, abri mão da possibilidade de fazer meu doutorado no exterior, o que me teria dado condições mais do que razoáveis para realizar minha pesquisa e preparar minha tese. Fernando Henrique Cardoso havia me sugerido que fizesse o doutorado com o professor Alessandro Pizzorno, sociólogo italiano. Eu, porém, havia, em princípio, optado por fazê-lo com o antropólogo Eric Wolf, nos Estados Unidos. As circunstâncias adversas em que haviam ficado os cursos de sociologia com as aposentadorias apoiadas no Ato Institucional n" 5 acabaram exigindo de vários de nós, que éramos poucos, a permanência. Destaque-se, apesar dos muitos problemas havidos ao longo dos anos seguintes, o papel corajoso que tiveram os professores Luiz Pereira e Marialice Mencarini Foracchi, assistentes do professor Florestan, que já eram doutores, na preservação de um compromisso básico com o projeto da antiga Cadeira de Sociologia I. 
3 Cf. Florestan Fernandes, Economia e sociedade no Brasil (Análise sociológica do subdesenvolvimento), Seção Gráfica da Faculdade de Filosofia, Ciências e Letras da Universidade de São Paulo, 1962.

4 Essas generosidade e grandeza tornaram-se ainda maiores se considerarmos que o professor Florestan e os católicos, especialmente a hierarquia católica, se encontraram em campos opostos no confronto radical motivado pela defesa que ele fez da escola pública, entre o fim dos anos 50 e início dos 60, na chamada Campanha de Defesa da Escola Pública. Ele nunca abandonou seus pontos de vista a esse respeito.

5 O professor Florestan Fernandes foi procurado por Fernando Henrique Cardoso, que o convidou a fazer parte do Cebrap, mas preferiu manter-se fora de instituições nãoacadêmicas

6 Nesse sentido, discordo de Fernando Henrique Cardoso quando, em belo artigo de homenagem a Antonio Candido, diz e lamenta que seu livro Os parceiros do rio Bonito não tenha feito escola: "A influência dos autores desse grupo nas gerações seguintes nem sempre se deu pela precisa continuidade das orientações teóricas e dos sistemas conceituais, mas sobretudo pela incorporação dos problemas (e não propriamente dos temas) de investigação que haviam formulado e proposto". A fome e a crença (sobre Os parceiros do rio Bonito), in Celso Lafer et alii, Esboço de figura (homenagem a Antonio Candido), São Pạulo, Livraria Duas Cidades, 1979, p. 92.

7 Merton refere-se ao trabalho de Florestan Fernandes, Ensaio sobre o método de interpretação funcionalista em sociologia, Boletim da Faculdade de Filosofia, Ciências e Letras da Universidade de São Paulo, $\mathrm{n}^{\circ}$ 170, 1953.

8 Refiro-me à conferência que Marshall pronunciou em Cambridge, em 25 de novembro de 1960. Cf. T.H. Marshall, Sociology at the crossroads and other essays, London, Heinemann, 1963, p. 25-43 (Sociology - the road ahead)

9 Cf. Florestan Fernandes, Fundamentos empíricos da explicação sociológica, São Paulo, Companhia Editora Nacional, 1959

José de Souza Martins é professor associado do Departamento de Sociologia da Faculdade de Filosofia, Letras e Ciências Humanas da USP, Fellow de Trinity Hall e professor titular da Cátedra Simón Bolivar (1993/94) da Universidade de Cambridge. Foi aluno e auxiliar de ensino do professor Florestan Fernandes na antiga Cadeira de Sociologia I da Faculdade de Filosofia.

Versão revista e ampliada da exposição feita pelo autor no Ato Presença de Florestan Fernandes, organizado pelo Instituto de Estudos Avançados na Sala do Conselho Universitário da USP em 5 de outubro de 1995. 